\title{
SOMA 15: O JOGO DA ESCOPA UTILIZADO COMO FERRAMENTA PARA O ENSINO DA MATEMÁTICA
}

\section{SUM 15: THE SCOPE GAME USED AS A TOOL FOR TEACHING MATHEMATICS}

\author{
Luís Fernando Alcântara de Falqui ${ }^{1}$ \\ Fernando Pereira de Souza²
}

\begin{abstract}
RESUMO: Este artigo discorre sobre um relato de experiência a respeito da utilização de um jogo de cartas, a escopa, enquanto instrumento de ensino de matemática, em sala de aula. Buscamos uma abordagem atrativa e de fácil absorção, despertando curiosidades e construindo pensamentos estratégicos intuitivos, de modo individual ou em grupos, trabalhamos alguns conceitos matemáticos, entre eles: raciocínio lógico, contagem e operações aritméticas básicas. Além de registrarmos a criatividade dos alunos, atuamos na comunicação entre os jogadores (em duplas), na observação de possibilidades e tomada de decisões e nas estratégias para o desenvolvimento do jogo, de forma lúdica e divertida através da gamificação. Ademais, procuramos variar e ampliar a utilização do material didático, nas aulas expositivas, na resolução de exercícios, como mais uma ferramenta para a aprendizagem, e assim, tentamos motivar alunos e professores, tornando o estudo dessa parte da Matemática mais dinâmica, significativa e prazerosa.
\end{abstract}

PALAVRAS-CHAVE: Ensino de Matemática; Cálculo Mental; Raciocínio Lógico; Contagem; Escopa.

\begin{abstract}
This article discusses an experience report on the use of a card game, the scope, as an instrument for teaching mathematics in the classroom. We seek an attractive and easy-to-absorb approach, arousing curiosity and building intuitive strategic thoughts, individually or in groups, we work with some mathematical concepts, including: logical reasoning, counting and basic arithmetic operations. In addition to recording the creativity of students, we work in communication between players (in pairs), in the observation of possibilities and decision-making and in strategies for the development of the game, in a playful and fun way through gamification. Furthermore, we seek to vary and expand the use of teaching material, in lectures, in solving exercises, as another tool for learning, and thus, we try to motivate students and teachers, making the study of this part of Mathematics more dynamic, meaningful and pleasurable.
\end{abstract}

KEYWORDS: Mathematics Teaching; Mental Calculus; Logical reasoning; Score; Scope.

\section{Introdução}

Inspirados pelas dificuldades na compreensão de conceitos e no desenvolvimento/aprimoramento de habilidades inerentes à disciplina de matemática, constantemente exigidos em grandes concursos, desenvolvemos tal experiência afim de contribuir para a diminuição de tais obstáculos, buscando maior integração entre os alunos,

\footnotetext{
${ }^{1}$ Pesquisador autônomo. E-mail: Iffalqui@hotmail.com.br https://orcid.org/0000-0001-7304-7377

2 Universidade Federal do Mato Grosso do Sul. fernando.pereira@ufms.br https://orcid.org/0000-0001-6441-0103
}

- Informações completas da obra no final do artigo 
entre alunos e professor, entre alunos e a Matemática, aspirando a redução no receio dos estudantes em investigar sobre suas dúvidas em relação a algum conceito ou habilidade desta disciplina, viabilizando uma aula mais dinâmica e aprazível, por meio da prática de um jogo de cartas. Possibilitar a compreensão de conteúdos matemáticos como contagem, raciocínio lógico e operações aritméticas básicas, para alunos do Ensino Médio e curso preparatório para vestibular, foi nossa motivação.

Pesquisadores da área de Ensino, dentre os quais destacamos Marcos Aurélio Cabral, em "A utilização de jogos no ensino de matemática", Regina Célia Grando, em "O Jogo suas possibilidades metodológicas no processo ensino-aprendizagem da matemática", Willians Freire Pires, em "O jogo de escopa adaptado para o uso em sala de aula", compartilham uma mesma conclusão sobre as abstrações encontradas na matemática e no ser humano. Segundo eles é necessário estimular os estudantes a apreciar e valorizar os conceitos que lhes serão transmitidos, contribuindo para a compreensão e desenvolvimento desses. Com base nisso, recorremos à utilização de jogos no ensino desta disciplina, com a intenção de trazer maior sentido e interesse para a aprendizagem de alguns tópicos, mediante a recreação, a interpretação e respeito às regras, a competição e o raciocínio que permeiam os jogos.

Em sua dissertação, Regina Célia Grando apresenta algumas respostas referentes à questão "Para você, o que é jogo?", dadas por professores de Matemática da Prefeitura de Campinas - SP e por alunos do curso de pedagogia da PUCCAMP - Campinas, corroborando com nosso entendimento descrito anteriormente:

Ao perguntarmos para várias pessoas sobre o que elas acreditam que sejam JOGOS, é muito comum ouvirmos respostas do tipo: "lazer, brincadeira, brincadeira regrada, desafio, divertimento emocionante, desenvolvimento do raciocínio, disputa, competição, divertimento que exige do jogador determinadas habilidades, passatempo, recreação, atividade que pode ser individual ou em grupo, atividade que tem regras pré-estabelecidas, atividade dotada de algum sentido lúdico..." (GRANDO, 1995, p. 46).

Entre os benefícios do uso de jogos no processo de ensino da matemática, podemos citar a aprendizagem de conceitos matemáticos, a obtenção de ganhos individuais em relação à tomada de atitude e resolução de problemas, que são fundamentais para o crescimento e formação de alunos críticos e lúcidos. Acordando com tais relações, citamos Marco Aurélio Cabral: 
A pretensão da maioria dos professores, com a sua utilização, é a de tornar as aulas mais agradáveis com o intuito de fazer com que a aprendizagem torne-se algo fascinante. Além disso, as atividades lúdicas podem ser consideradas como uma estratégia que estimula 0 raciocínio levando 0 aluno a enfrentar situações conflitantes relacionadas com seu cotidiano e, também, a utilização dos jogos vem confirmar o valor formativo da matemática, não no sentido apenas de auxiliar na estruturação do pensamento e do raciocínio dedutivo, mas, também, de auxiliar na aquisição de atitudes (CABRAL, 2006, p. 19).

Ampliando o contexto da utilização dos jogos no ensino da matemática para o âmbito psicológico, tanto na área da psicomotricidade quanto na área afetivo-social, apontamos sua relação direta com a construção da inteligência, ressaltando o prazer, a motivação, a formação de valores como respeito e honestidade, de acordo com Piaget. Mencionamos, a seguir, Pacagnam e Nishihara, destacando essas concepções piagetianas, salientando que, em um jogo, existe vencedor e vencido:

Jogos práticos são aqueles que as crianças fazem explorações sensórias-motores, jogos simbólicos, aos poucos as crianças vão adquirindo a imitação, o faz de conta e os jogos de regras que são utilizados até a fase adulta, sendo necessário que a criança aprenda o significado e a importância das regras para então poder relacioná-las com as regras que utilizamos em nosso convívio social (PACAGNAM, 2013, p. 20).

Os jogos podem ser utilizados para fins educacionais para transmitir o sentido de respeito às regras e a mensagem de que numa disputa entre adversários haverá sempre um que perde e outro que ganha (NISHIHARA, 2016, p. 2).

O baralho de cartas padrão é um manipulador de baixo custo, facilmente encontrado em todas as partes mundo, e com bom potencial para ser utilizado por professores e alunos, sendo capaz de amplificar a modelagem, a motivação e o ensino de habilidades e técnicas no raciocínio lógico, resolução de problemas, noções de conjuntos, estatística elementar, teoria dos jogos, matemática para negócios e probabilidade elementar. Tudo isso é possível através de atividades interativas focadas no conteúdo proposto, apresentando uma abordagem alternativa para alunos desencantados com o currículo tradicional proposto para a Matemática. Ressaltamos que o uso de jogos não deve substituir a apresentação teórica dos conceitos, mas sim, vir como uma alternativa para atrair e aguçar os estudantes.

Expomos, também, nossa preocupação em utilizar o baralho de forma simples e natural, de modo que não houvesse conflito com pais de alunos ou responsáveis, esclarecendo sobre a sua relevância, no aprendizado dos temas a serem abordados. Pires também traz esse receio em seu trabalho, atentando para o preconceito que pode estar embutido na utilização das cartas, no ambiente escolar: 
Embora os jogos de cartas tenham uma grande intimidade com a Matemática, no ambiente escolar, a prática desse tipo de jogo ainda é um tabu. Sendo assim, a proposta é fazer uma adaptação estética e, principalmente, das regras do jogo, de modo a deixá-lo atraente e capaz de cumprir um papel pedagógico (PIRES, 2016, p.23).

Decidimos pela utilização de um jogo acessível, tanto em relação à sua compreensão quanto ao seu desenvolvimento. Seu principal objetivo é combinar uma ou mais das cartas sobre a mesa com uma daquelas que o jogador possui em suas mãos, obtendo soma igual a 15, possibilitando, assim, o trabalhar das operações básicas mentalmente, o raciocínio lógico e a contagem, na associação de parcelas, com propósito do jogo seguir favoravelmente a cada jogador, acordando com suas devidas táticas e técnicas, que podem promover ganhos educacionais, pensando nas resoluções de exercícios que certamente exigirão certas habilidades desses alunos. Citamos Pires novamente, com uma apresentação sucinta do jogo escopa e sua origem:

A escopa ou escopa de 15 é um tradicional jogo de cartas de baralho trazido ao Brasil pelos imigrantes italianos. O nome escopa vem da palavra scopa que, em italiano, significa vassoura. Pode ser jogado entre duas, três ou quatro pessoas, nesse caso, em parceria, e utiliza-se do Baralho Espanhol (PIRES, 2016, p.22).

\section{O jogo}

No jogo escopa, é utilizado um baralho com quarenta cartas (denominado baralho espanhol), sendo dez cartas de cada naipe:

- Cartas: A (ÁS), DOIS, TRES QUATRO, CINCO, SEIS, SETE, Q (DAMA), J (VALETE), K (REI);

- Naipes: ouros, espadas, copas e paus.

As cartas que não apresentam valores numéricos em suas imagens, nomeadas figuras do baralho, têm os seguintes valores: ÁS vale um (1), Q vale oito (8), J vale nove (9) e K vale dez (10). Segue também que as cartas de ouro (símbolo) têm maior importância, especialmente, A, SETE, Q e K, chamados "belos" (Figura 1). As cartas de número SETE dos demais naipes também têm sua importância. Tais valores serão apresentados a posteriori. 


\section{ENSIN@UFMS 2021}

ISSN 2525-7056

Figura 1. Os belos

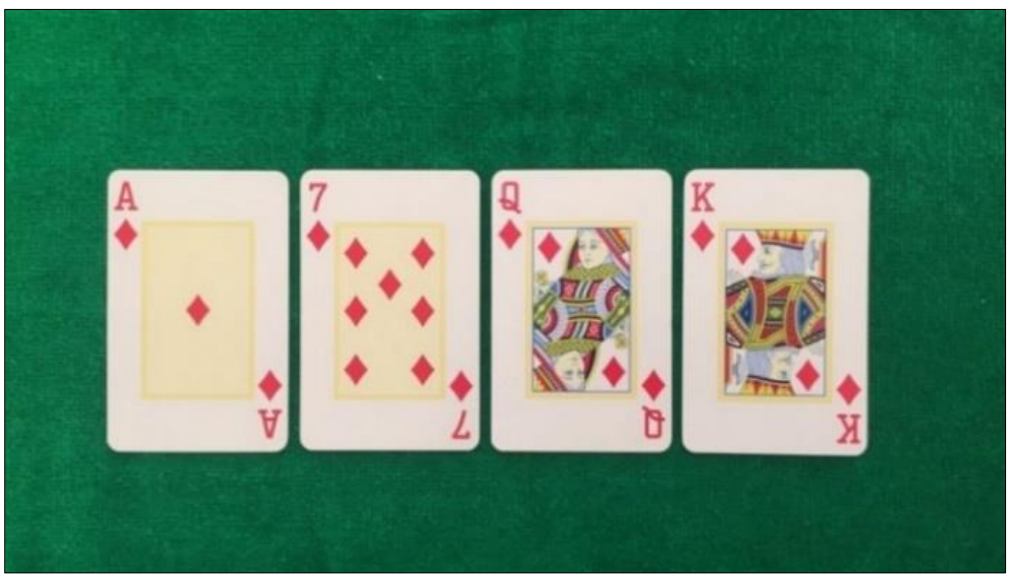

Fonte: Autor

A essência do jogo consiste em somar 15 pontos em cada jogada, e, caso isso seja feito com o recolhimento de todas as cartas da mesa, combinadas com uma do próprio jogador, é feita uma escopa. Cada partida pode ser jogada individualmente, um contra um, ou com três jogadores distintos se enfrentando. Também pode se desenvolver com o enfrentamento em duplas, alternando os jogadores das duplas a cada jogada, seguindo os padrões citados a seguir.

Inicia-se uma partida com um dos jogadores entregando três cartas para cada um dos demais e, abrindo outras quatro sobre a mesa. Esse jogador, escolhido por sorteio ou acordo entre os participantes, é denominado "pé do baralho". As cartas são distribuídas com uma condição: a primeira carta deve ser entregue, necessariamente, ao jogador à direita do "pé", esse é chamado "mão do baralho". As demais cartas são entregues de acordo com o desejo do embaralhador, respeitando as quantidades anteriormente mencionadas.

Cada jogador utiliza apenas uma de suas cartas por vez. Com isso, em cada rodada os jogadores descartam três cartas, iniciando-a sempre pelo "mão" e terminando-a pelo "pé". Após as primeiras três cartas de cada jogador serem jogadas, o "pé" volta a distribuir mais três cartas para cada jogador, até que elas acabem.

Assim, a rodada tem início. Se o "mão" combinar uma de suas cartas com alguma(s) outra(s) da mesa, somando 15, recolhe-as e começa a formar seu monte de cartas para que, ao final das rodadas sejam contados e somados seus pontos, caso não consiga somar 
15, ele deve descartar uma de suas cartas sobre a mesa para que o próximo jogador faça sua jogada. Analogamente, sempre em sentido anti-horário, cada jogador faz o mesmo.

Voltamos a citar Pires, que evidencia algumas jogadas em seu estudo, detalhando as combinações de algumas cartas para somar 15, propósito fundamental do jogo.

Por exemplo: na mesa estão os números $5,3,7,6$. Se o jogador tiver o número 8 , poderá juntar com o número $7(8+7=15)$ e formar seu monte. Se o jogador tiver o número 1 poderá juntar com os números 5 , 3 e $6(1+5+3+6=15)$ e formar seu monte. Se o jogador tiver o número 9 , poderá juntar com todas as cartas da mesa e formar seu monte $(9+5+3+7+6=30)$ (PIRES, 2016, p.25).

Eventualmente, ao virar as quatro cartas sobre a mesa, o "pé" pode obter soma 15. Por exemplo: ao virar um às, um três, um quatro e um sete, a soma dessas é igual a 15 (Figura 2). Neste caso, ele recolhe as cartas para si e anota uma escopa. Dando continuidade ao jogo, o "mão" descartando uma de suas cartas, já que não poderá recolher nenhuma. Na virada inicial do "pé", existe uma única possibilidade de se fazer duas escopas, que é obter dois pares, cada um deles somando 15. Por exemplo: ao virar um CINCO, um K, um SETE e um Q, já que, CINCO mais K é igual a 15, SETE mais Q, também (Figura 3).

Figura 2. Escopa

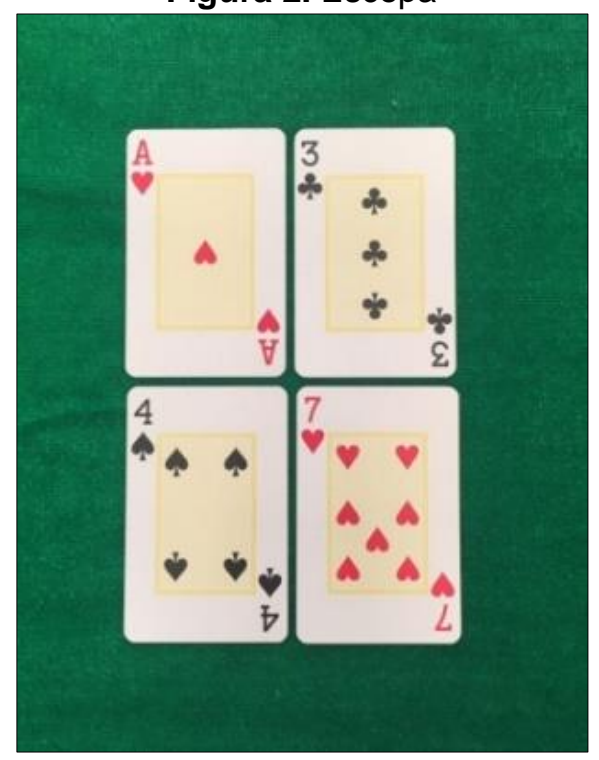

Fonte: Autor 
Figura 3. Par de escopas a partir da virada efetuada pelo "pé"

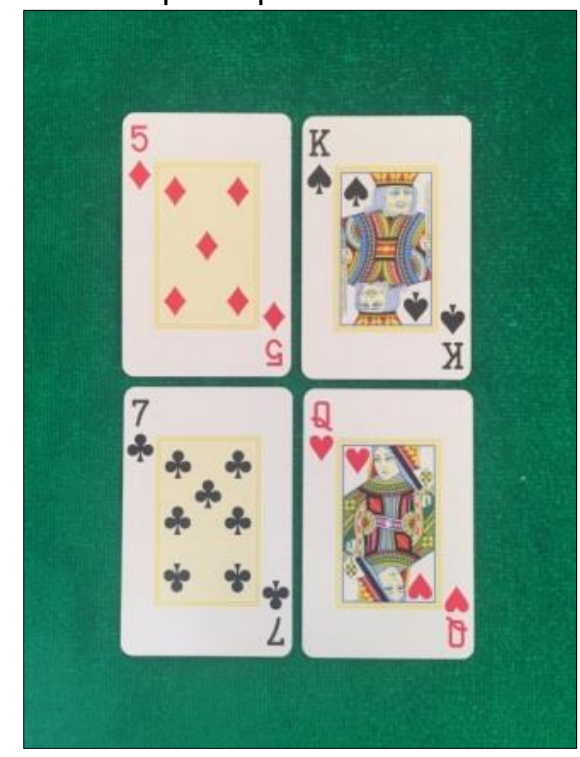

Fonte: Autor

Cada escopa (somar 15 pontos recolhendo todas as cartas da mesa, como já citado anteriormente) vale um ponto. Além disso, existem sete pontos fixos, chamados "pontos do baralho":

I. Cada belo vale um ponto. Seguem 4 pontos no total;

II. O jogador ou dupla que tiver maior número de cartas SETE, ganha um ponto. Em caso de empate, ninguém pontua;

III. O jogador ou dupla que tiver maior número de cartas de ouro, ganha um ponto. Em caso de empate, ninguém pontua;

IV. O jogador ou dupla que tiver maior número de cartas totais, ganha um ponto. Em caso de empate, ninguém pontua.

Despercebido, um jogador descarta uma carta que, combinada com outra(s) somava 15. Percebendo o equívoco, o próximo jogador pode recolher as cartas para si antes de realizar sua jogada. A última rodada se dá com uma escopa, ou remanescerão cartas sobre a mesa. A soma dos valores de tais cartas são, obrigatoriamente, 10, 25, 40 ou 55 pontos, acordando as cartas excedentes com a divisibilidade por 15 da soma total dos pontos com os valores das cartas, que é igual a $220[(1+2+3+4+5+6+7+8+9+10) \cdot 4=220]$. Decorrendo a soma de tais cartas com valor diferente destes, algum jogador cometeu erro na sua recolhida. Encontrada a infração, uma penalidade, previamente discutida e aderida por todos, deve ser dada ao jogador ou dupla que a cometeu. 
O fim do jogo se dá quando um dos jogadores ou dupla obtêm 15 pontos, independentemente da quantidade de rodadas. Como esta pontuação é variável, deve ser decidida de antemão. Alguns preferem que o jogo vá até 21, 25, 31 pontos. A única semelhança é que o final vem com uma quantidade ímpar de pontos, reduzindo a possibilidades de empates com uma quantidade par de pontos.

\section{A Matemática em jogo}

Retomando as ideias inicialmente tratadas, salientamos a utilização do jogo de cartas, em especial a escopa, como base para o desenvolvimento deste estudo, por todo o contexto favorável que a gamificação traz para a educação, sobretudo em conteúdos e habilidades matemáticas, dentre estes: raciocínio lógico, operações básicas e cálculos mentais, números naturais e inteiros, contagem, análise combinatória, e probabilidade. Grando também discorre sobre este ponto:

Quando se propõe a utilização de jogos no contexto educacional de ensinoaprendizagem, muitas são as finalidades que se quer atingir. Entre elas, destacamse: a fixação de conceitos, a motivação, a construção de conceitos, aprender a trabalhar em grupo, propiciando solidariedade entre os alunos, estimular a raciocinar, desenvolver o senso crítico, a disposição para aprender e descobrir coisas novas, além do desenvolvimento da cidadania (GRANDO, 1995, p. 86).

Apresentamos a seguir, alguns exemplos que foram trabalhados devido à abordagem feita por parte dos alunos no decorrer dos jogos, ou por pensamento prévio para a adequação da introdução de algum conceito específico, o qual será mencionado previamente, de modo prático e visual, familiarizando as cartas com esses tópicos da Matemática.

O raciocínio lógico é essencial para a resolução de problemas, o que pode significar um trampolim para o sucesso acadêmico, profissional e até mesmo pessoal. Instigar o desenvolvimento do raciocínio lógico nos alunos ajuda a melhorar as suas habilidades com as operações básicas e os cálculos mentais, resultando em níveis mais altos de atividade cognitiva e numa maior capacidade de resolver problemas. A escopa estimula o raciocínio lógico a cada cartear, como mostra o exemplo aplicado em sala de aula.

Exemplo 1: Na mesa há um QUATRO e um OITO, e o jogador possui em suas mãos as cartas ÁS E NOVE. O que será mais vantajoso nesta situação? 
Podemos observar que, ao jogar a carta Ás, se facilita a possibilidade do próximo jogador, no caso um oponente, efetuar uma escopa, pois as cartas que ficarão na mesa terão soma menor que quinze $(4+8+1=13)$. Ou seja, uma posterior carta DOIS $(4+8$ $+1+2=15$ ), garante a recolhida de todas as cartas. Agora, se é jogada a carta NOVE, a soma supera quinze $(4+8+9=21)$, impossibilitando a feitura de uma escopa na próxima jogada.

Exemplo 2: Tendo em mãos um TRÊS e um CINCO, qual dessas cartas eu devo jogar, havendo um DOIS e um K na mesa?

Ponderando as possibilidades, consideramos que jogar o TRÊS é a melhor escolha, já que, com esse movimento, uma escopa será feita, pois a soma dessas três cartas resulta quinze $(2+10+3=15)$. Com a carta CINCO, o jogador em questão recolhe apenas a carta $K(5+10=15)$, deixando a carta DOIS na mesa, e não efetua a escopa, o que é bastante significativo no jogo.

A importância das habilidades e estratégias utilizadas na realização de cálculos mentais e suas estratégias é inegável, considerando sua utilidade na vida cotidiana em comparação com alguns dos algoritmos escritos. Além disso, a prática desses cálculos contribui para o desenvolvimento de vários conceitos e habilidades matemáticas, como senso numérico mais profundo e inúmeras habilidades cognitivas, como proficiência e flexibilidade entre estratégias usadas em situações problema, em diferentes domínios matemáticos. O cálculo mental é utilizado com frequência durante o jogo, como podemos observar no seguinte exemplo.

Exemplo 3: Uma rodada é finalizada e, sobra na mesa, uma de cada das seguintes cartas: ÁS, TRÊS e QUATRO. Quais as opções para o "mão" recolher todas ou algumas dessas?

Primeiramente, o jogador deve calcular mentalmente que, a soma das cartas da mesa é igual a $8(1+3+4)$. Assim, teremos as seguintes alternativas:

- Com um SETE, o jogador faz uma escopa, pois, com os 8 pontos da mesa, previamente mentalizados, basta calcular que, para a soma ser igual a 15 , faltam 7 pontos $(8+7=15)$; 
- Com um Q, o jogador recolhe o TRÊS e o QUATRO, haja visto que $Q$ vale 8 pontos, e, para fazer uma escopa, são necessários outros 7 pontos disponíveis na mesa, calculados com as cartas TRÊS e QUATRO $(3+4+8=15)$;

- Com um K, o jogador recolhe o ÁS e o QUATRO. Seguindo com o cálculo mental, como $\mathrm{K}$ vale 10 , com mais 5 pontos da mesa, chega-se nos 15 pontos desejados $(1+4+10=15)$

- Nas demais situações, o jogador não poderá recolher, apenas descartar. Nesse momento, sua jogada é tão importante quanto àquela que recolhera cartas para si, pois ele deve se atentar, mentalizar e mentalmente calcular que, como existem 8 pontos na mesa, tem de jogar algo que ultrapasse os 15 pontos, impossibilitando que seu oponente faça uma escopa na jogada seguinte. Assim, a melhor jogada se dá com o descarte de um J, que vale 9 , e a soma de 9 com os 8 pontos da mesa é 17; caso contrário, a soma será sempre menor que 15.

A análise combinatória é um significativo componente do currículo de matemática, interligado com as regras e princípios de contagem e com as áreas da Computação e Probabilidade. Para tratar desse assunto, a escopa exige, por parte dos alunos, conhecimentos mais aprofundados, pois o cálculo de probabilidades se torna complicado quando é feito mentalmente. Porém, trabalhamos a combinatória, nesse jogo, com exercícios mais teóricos, dando maior profundidade a esses conceitos e habilidades, como mostra o exemplo seguinte.

Exemplo 4: Qual a chance de o "pé" do baralho fazer uma escopa, logo na primeira rodada, ou seja, ao virar as 4 cartas iniciais da mesa?

Para que o "pé" faça uma escopa ao distribuir as primeiras cartas, as 4 que irão compor a mesa devem somar 15 . Assim, para calcular o número destas possibilidades, respeitando os valores das cartas, devemos resolver uma equação do tipo, $\mathrm{x}+\mathrm{y}+\mathrm{z}+\mathrm{w}=$ 15 , sendo $x, y, z, w \in \mathbb{N}$ e $0<x, y, z, w \leq 10$. Com tais restrições, damos uma unidade para cada uma das variáveis e, com isso, teremos a equação $x^{\prime}+y^{\prime}+z^{\prime}+w^{\prime}=11$. Esta, com resolução mais simples, será análoga à anterior ao retirarmos as 4 seguintes possibilidades, que apresentam o número zero nas soluções: $(11,0,0,0),(0,11,0,0),(0,0,11,0),(0,0,0$, 11). Devemos pensar que tal resolução significa partir 11 unidades em 4 partes. Daí, 
representaremos cada solução por uma fila de sinais + e |, sendo que as barras são utilizadas para separar as incógnitas e a quantidade de sinais + indica o valor de cada uma. Por exemplo, a solução $(2,5,1,3)$ é representada por: $++|+++++|+\mid+++$. Logo, são 14 símbolos no total, com repetição de 3 | e $11+$. Calculamos as possibilidades por meio de uma combinação com repetição, ou uma permutação com repetição, que, nesse caso, são equivalentes, como mostra o desenvolvimento dos cálculos, destacando que, uma permutação com duas repetições que, somadas resultam o total de elementos, tem a característica de desordem de uma combinação:

$$
\mathrm{Cr}_{11,3}=\mathrm{C}_{14,3}=\mathrm{P}_{14}^{3,11}=\frac{14 !}{3 ! \cdot 11 !}=\frac{14 \cdot 13 \cdot 12 \cdot 11 !}{3 \cdot 2 \cdot 1 \cdot 11 !}=14 \cdot 13 \cdot 2=364 \text {. }
$$

Calculemos agora, a probabilidade de esta jogada ocorrer, denominando tal evento pela letra A.

A: As quatro cartas iniciais da mesa somarem 15;

$$
\mathrm{n}(\mathrm{A})=364-4=360 \text {. }
$$

O número de elementos do espaço amostral será obtido com uma combinação $\mathrm{C}_{40,4}$, já que das 40 cartas do baralho, 4 serão viradas sobre a mesa, independentemente da ordem que isso for feito.

$$
\begin{aligned}
& \qquad \mathrm{n}(\mathrm{E})=\mathrm{C}_{40,4}=\frac{40 !}{4 ! \cdot 36 !}=\frac{40 \cdot 39 \cdot 38 \cdot 37 \cdot 36 !}{4 \cdot 3 \cdot 2 \cdot 1 \cdot 36 !}=5 \cdot 13 \cdot 38 \cdot 37=91390 \\
& \text { Portanto, } \mathrm{P}(\mathrm{A})=\frac{\mathrm{n}(\mathrm{A})}{\mathrm{n}(\mathrm{E})}=\frac{360}{91390}=\frac{180}{45695} \cong 0,004=0,4 \% \text {. }
\end{aligned}
$$

Ademais, o ensino de Matemática não precisa ser desenvolvido somente por meio de aulas expositivas e resolução de exercícios. As estratégias de jogo, como vistas em nosso trabalho, "provoca" o aluno de modo que ele desenvolva cálculos mentais e estratégias para resolver situações problema. Também estimulam o desenvolvimento de sua capacidade de tomada de decisões e de trabalho em grupo quando, nesse jogo, os princípios de contagem e o conceito de probabilidade apontam como combinar os movimentos e quais as possibilidades de obter sucesso nas jogadas e, portanto, vencer o jogo.

A importância de trabalhar a matemática recorrendo a jogos, também é abordada por Júlia Borin, acentuando os conceitos que descrevemos e exemplificamos anteriormente, os quais acrescentam valor para o ensino matemático e para a resolução de problemas do dia a dia, estendendo o trabalho para além da sala de aula: 
Especialmente na aula de Matemática, se bem aplicado, o jogo pode ajudar a desenvolver diversas habilidades de raciocínio, como a organização, a atenção e a concentração. Também auxilia na descentralização, na capacidade de se observar algo de outro ponto de vista que não o seu. Tais habilidades são essenciais ao ensino da Matemática e à resolução de problemas em geral (BORIN, 2004, p.).

\section{A execução do projeto}

No início do ano letivo de 2018 o trabalho foi apresentado às três escolas em que eu lecionava. O tabu existente sobre a utilização do baralho e dos jogos de cartas, em sala de aula, trouxe empecilhos para a aplicação das atividades previamente propostas, já que os gestores das instituições e os pais dos alunos ou responsáveis consideravam esta prática inadequada ao ambiente escolar, seja por serem vistos como jogos de azar, por estarem ligados aos bares, cassinos e ambientes similares, por motivos religiosos, ou pela falta de horário na grade dos alunos.

Então, procuramos um curso especializado em exatas, onde consideramos que a execução do projeto teria maior chance de aceitação e ser realizada, tendo em vista a heterogeneidade dos alunos que, tentando alcançar diversos níveis de competências e habilidades, buscam este tipo específico de curso. Alguns visam a abordagem de conteúdos mais simples, com seus enfrentamentos às dificuldades trazidas pela deficiência no conhecimento de matemática básica, e outros, com algumas habilidades já adquiridas, tentam alcançar um nível de conhecimento que possibilite obterem aprovação no vestibular.

Por eu também trabalhar nessa instituição onde foi permitido realizar esse estudo, começamos a divulgar nossas pretensões para os alunos, deixando claro quais atividades iríamos executar, e podemos verificar mais de perto, qual seria o nível de aceitação dessa proposta. Contudo, o projeto foi bem aceito e então, enviamos autorizações a seus pais e/ou responsáveis para que pudéssemos utilizar os jogos de cartas em aulas previamente definidas, acordando com os cursos já ministrados, e assim, empregamos a escopa em duas noites.

No primeiro encontro, sete alunos receberam as instruções sobre as regras do jogo e quais conceitos matemáticos seriam abordados na escopa. Além deles, estava presente um outro professor, felizmente conhecedor do jogo, contribuindo para que jogássemos uma partida inicial. Assim, apresentamos o jogo na prática, explicando, algumas vezes, o porquê das jogadas que fazíamos, mostrando as possibilidades futuras, a cada cartear. 
Em sequência, um dos alunos substituiu o professor que jogou a primeira partida, seguindo com a mesma ideia de apresentar as possibilidades das jogadas. Depois, foi sugerido que eles jogassem entre si e nós professores fossemos assistindo-os em suas dúvidas. Assim, fizemos.

A presença de outra pessoa que sabia como lidar com a escopa foi de grande importância, uma vez que era um jogo desconhecido pelos alunos. No entanto, observamos que, caso isso não seja possível, o professor instrutor pode utilizar os mais variados sites ou aplicativos, para jogar e fazer as devidas apresentações, auxiliando os alunos em suas noções preliminares.

O receio em jogar "errado" foi a marca das primeiras rodadas. Com o passar do tempo e das jogadas, com as indicações/mediações dos professores, os alunos se sentiram mais à vontade e jogaram à vera. Ao fim da aula, já tendo ultrapassado o horário combinado (resultado da empolgação dos jogadores), foi pedido para que voltássemos em outra oportunidade para continuar com as partidas. Desse modo, julgamos ter sido, além de gratificante, de suma valia a utilização da escopa para ampliar as ferramentas para o aprimoramento das habilidades daqueles que estão em busca de aprendizado e aprovações.

Acentuando a principal característica da primeira noite de escopa, o receio ao descartar, apresentamos algumas das jogadas que advieram no transcorrer das partidas, exemplificando com as dúvidas expostas pelos novos jogadores.

Exemplo 5: Tendo em mãos um TRÊS e um CINCO, qual destas cartas devo jogar, havendo outro TRÊS na mesa?

Como dito acima, a jogada consistia em um jogador ter em mão TRÊS e CINCO, além de haver um TRÊS na mesa. Ponderando as possibilidades, consideramos que jogar outro TRÊS é a melhor escolha, já que desse modo, o jogador seguinte poderá apanhar as cartas somente com um J. Com a carta CINCO, o oponente recolhe cartas com um SETE ou com K. Por esse motivo, é primordial observar as cartas já utilizadas anteriormente para poder analisar qual jogada menos favorece o adversário. 
Exemplo 6: Caso eu não consiga pegar nenhuma das cartas que estão na mesa, o que devo jogar?

Depende muito das cartas apresentadas na mesa e daquelas que já foram utilizadas. Contudo, apresentamos algumas dicas para essa situação, salientando a pontuação da escopa:

I. Não jogar belos, pois cada um desse vale 1 ponto;

II. Deixar o valor total das cartas da mesa acima de 15 pontos. Assim seu adversário não pode fazer uma escopa;

III. Não permitir que o oponente pegue um belo que tenha em mãos com as cartas da mesa. Por exemplo, evitar deixar uma carta CINCO, a qual possibilita utilizar o $\mathrm{K}$ de ouro;

IV. Evitar jogar SETE, ou que seu opositor possa utilizar um SETE para obter cartas da mesa, pois quem tiver mais cartas SETE ao final do jogo, ganha 1 ponto;

V. Jogar cartas que já estão na mesa, propiciando menos combinações para as cartas do próximo jogador.

No segundo encontro, nove alunos, sendo três novos e seis que já haviam participado da aula anterior, compareceram para a nova atividade. Como alguns desse já conheciam o jogo, tivemos uma boa oportunidade para observarmos o nível de aprendizado daqueles que já tínhamos orientado na prática do jogo de escopa. Assim, decidimos que os alunos que participaram do primeiro encontro seriam monitores daqueles que ainda não conheciam o jogo, análogo ao que fizemos na primeira noite. Demos assistência em alguns momentos introdutórios, recordando algumas regras ainda não absorvidas pelos monitores, e em jogadas específicas, seja por uma grande quantidade de opções ou por erros de execução que passaram despercebidos. Após todos estarem aptos a jogar e melhor compreender a relação entre escopa e matemática, passamos a discutir sobre exercícios por nós elaborados, aduzindo conceitos específicos como: conjuntos numéricos, contagem e probabilidade, aspirando atar a prática do jogo, com o cotidiano dos alunos e vestibulandos. 


\section{ENSIN@UFMS 2021}

ISSN 2525-7056

Figura 4. Alunos jogando em duplas

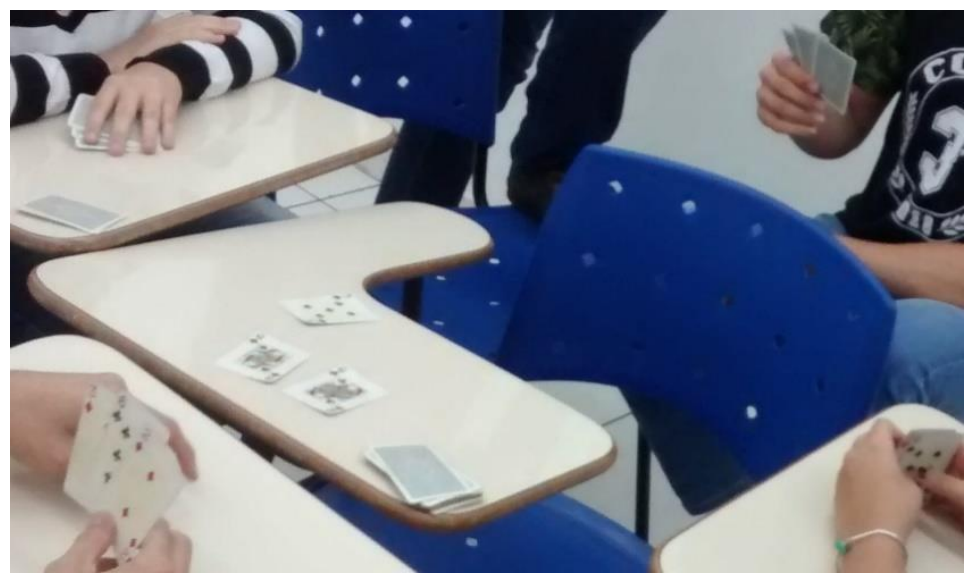

Fonte: Autor

Figura 5. Alunos jogando individualmente

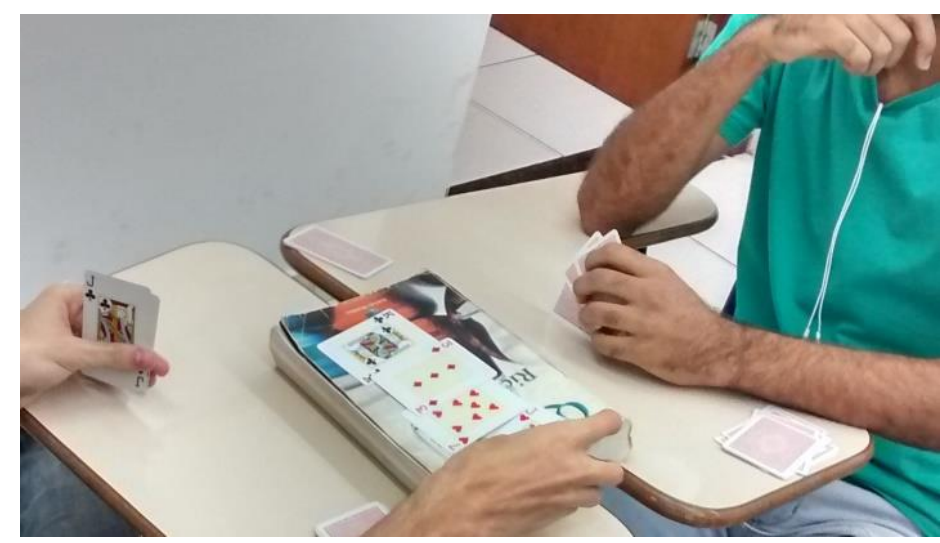

Fonte: Autor

\section{Considerações finais}

O projeto não foi aplicado/desenvolvido como gostaríamos, pois, enfrentamos barreiras devido à utilização do baralho, tanto por parte das instituições como dos pais dos alunos ou responsáveis. Mesmo questionando-os sobre a utilização de jogos e aplicativos com abordagem análoga, e até fazendo a apresentação de um baralho (Figura 6) criado pelo Prof. Dr. Fernando Pereira de Souza, docente lotado na UFMS - CPTL, em conjunto com orientandos da graduação, trazendo personagens e símbolos matemáticos históricos, contextualizando o baralho com a Matemática, enfatizando suas origens e grandes pensadores, não permitindo a utilização do baralho comum, principal ponto de resistência das instituições. Porém, não foram argumentos e ferramentas suficientes para uma maior e melhor aceitação, em termos quantitativos. 
Figura 6. Baralho criado pelo Prof. Dr. Fernando Pereira de Souza

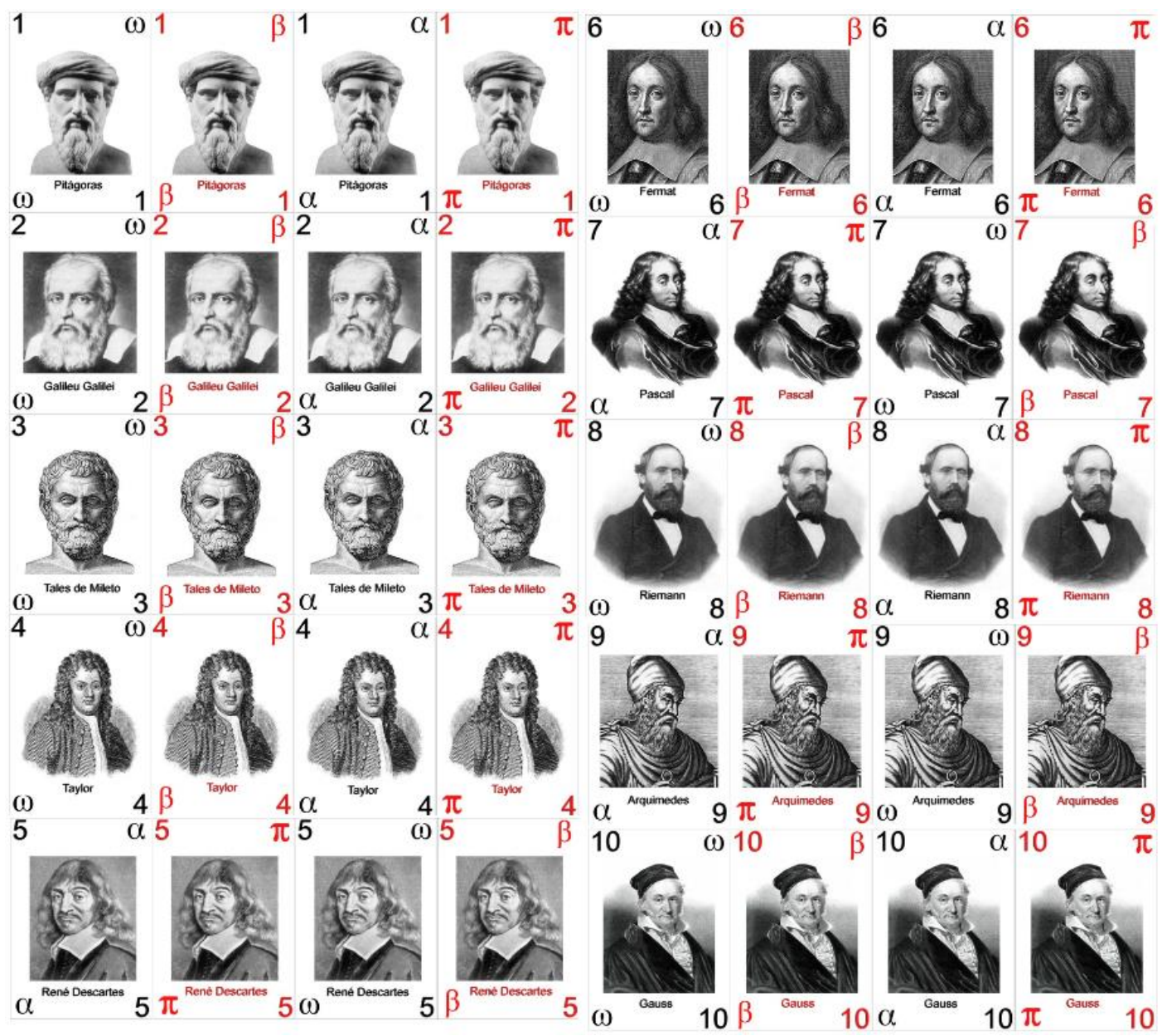

Fonte: Prof. Dr. Fernando Pereira de Souza

Além do baralho apresentado anteriormente, é oportuno propor que os próprios estudantes confeccionem suas cartas, explorando sua criatividade e habilidades, possibilitando a maior aproximação e consequente envolvimento com o projeto.

A interdisciplinaridade também pode ser trabalhada se utilizarmos "novos" baralhos, cunhados com outras imagens ou figuras que, além de estabelecer relações entre várias disciplinas, podem acrescentar valor qualitativo e maior interação e integração entre os professores e demais colaboradores das instituições. Apresentamos algumas opções para a troca das figuras originais do baralho, objetivando a interdisciplinaridade e seus propósitos:

- Objetos históricos como as Pirâmides, a Torre Eiffel, a Torre de Pisa. Objetos utilizados nas grandes guerras ou no holocausto; 


\section{ENSIN@UFMS 2021}

ISSN 2525-7056

- Presidentes, governadores e demais políticos que marcaram a história de seus países e estados;

- Esportistas memoráveis, objetos utilizados em esportes menos conhecidos;

- Flores, árvores, plantas, animais, sejam em extinção ou que representem símbolos de destaque;

- Representação dos números em formatos remotos (romano, grego, etc.) ou escritos em línguas estrangeiras ou indígenas.

Figura 7. Cartas com diferentes representações

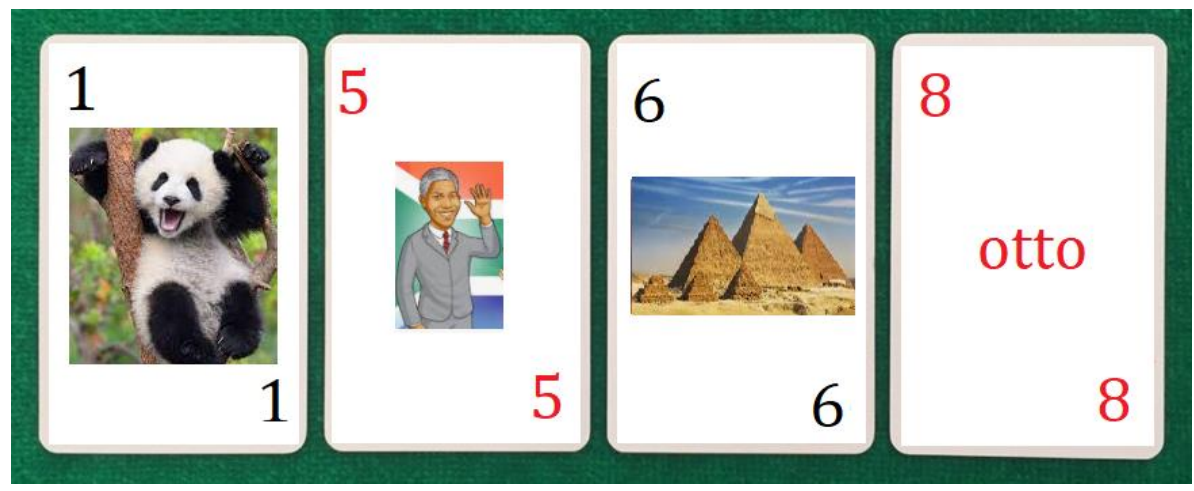

Fonte: Autor

Salientamos a utilização do jogo de cartas como instrumento de motivação e prazer para a introdução de conceitos tratados, por muitos alunos, como os mais difíceis para compreensão, muitas vezes pontos determinantes para não aprovações em exames e desmotivação no aprendizado de outros conteúdos. Filgueira traz pensamento similar, conforme apresentamos a seguir:

Através dos jogos podemos desenvolver atividades prazerosas, que estimulam aprendizagem em várias disciplinas, principalmente na Matemática, que é vista pelos alunos como uma grande vilã, muitos não gostam dessa disciplina, encontrando muita dificuldade em aprender o conteúdo da matéria, talvez pela maneira tradicional que o professor a apresenta, pelas cópias e mais cópias cansativas, exercícios repetitivos e mecanizados de fórmulas e regras, assim desmotivando os alunos a aprender (FILGUEIRA, 2018, p.2).

Considerando que, nas noites em que a escopa foi apresentada e realizamos o jogo, pudemos perceber a curiosidade iminente em cada participante assim como uma boa assimilação dos conteúdos introduzidos, concluímos ter sido gratificante e de suma valia a 
utilização da escopa como mais uma ferramenta para o aprimoramento das habilidades e competências, no processo de ensino e aprendizagem.

\section{Referências}

BORIN, J. Jogos e resolução de problemas: uma estratégia para as aulas de matemática. São Paulo: IME-USP, 2004.

CABRAL, M. A. A utilização de jogos no ensino de matemática. Dissertação (Graduação em Matemática) - Centro de Ciências Físicas e Matemáticas, Universidade Federal de Santa Catarina, Florianópolis, 2006. Disponível em: http://repositorio.ufsc.br/xmlui/handle/123456789/96526. Acesso em: 24 mar. 2021.

FILGUEIRA, L. A. B. V. A utilização dos jogos no ensino de matemática nos anos iniciais do ensino fundamental. Centro Universitário Mário Palmério - Unifucamp. Monte Carmelo, 2018. Disponível em:

http://repositorio.fucamp.com.br/jspui/handle/FUCAMP/100. Acesso em: 01 abr. 2021.

GRANDO, R. C. O Jogo suas possibilidades metodológicas no processo ensinoaprendizagem da matemática. Dissertação (Mestrado em Educação) - Faculdade de Educação, Universidade Estadual de Campinas, Campinas, 1995. Disponível em: http://repositorio.unicamp.br/jspui/handle/REPOSIP/253786. Acesso em: 24 mar. 2021.

NISHIHARA, A. Jogos na educação matemática: um olhar das pesquisas acadêmicas brasileiras para o ensino médio. ENCONTRO NACIONAL DE EDUCAÇÃO MATEMÁTICA, XII, 2016, São Paulo.

PACAGNAM, L. O jogo como estimulação para o desenvolvimento da criança na educação infantil. Dissertação (Especialista na Pós-graduação em Educação) Universidade Tecnológica Federal do Paraná, Medianeira, 2013. Disponível em: http://riut.utfpr.edu.br/jspui/bitstream/1/20743/2/MD_EDUMTE_II_2012_10.pdf. Acesso em: 01 abr. 2021.

PIRES, W. F. O jogo de escopa adaptado para o uso em sala de aula. Dissertação (Mestrado em Matemática em Rede Nacional) - Faculdade de Ciências e Tecnologia, Universidade Estadual Paulista "Júlio de Mesquita Filho", Presidente Prudente, 2016. Disponível em: http://hdl.handle.net/11449/134314. Acesso em: 24 mar. 2021.

\section{NOTAS}

\section{IDENTIFICAÇÃO DO TEXTO}

O presente texto é resultado da Dissertação de Mestrado do primeiro autor apresentada na Universidade Federal de Mato Grosso do Sul (UFMS), em 2018, sob a orientação do Professor Dr. Fernando Pereira de Souza. 


\section{IDENTIFICAÇÃO DE AUTORIA}

Luís Fernando Alcântara de Falqui. Mestre em Matemática pelo Programa de Mestrado Profissional em Rede Nacional (PROFMAT), pela Universidade Federal do Mato Grosso do Sul, Campus Três Lagoas. Pesquisador autônomo.

E-mail: Iffalqui@hotmail.com.br

https://orcid.org/0000-0001-7304-7377

Fernando Pereira de Souza. Doutor em Matemática pela Universidade Estadual de Campinas (UNICAMP). Professor Adjunto da Universidade Federal do Mato Grosso do Sul (UFMS), Três Lagoas, MS, Brasil.

E-mail: fernando.pereira@ufms.br

https://orcid.org/0000-0001-6441-0103

\section{AGRADECIMENTOS}

Não se aplica.

\section{FINANCIAMENTO}

Não se aplica.

\section{CONSENTIMENTO DE USO DE IMAGEM}

Não se aplica.

\section{APROVAÇÃO DE COMITÊ DE ÉTICA EM PESQUISA \\ Não se aplica.}

\section{LICENÇA DE USO}

Autores mantêm os direitos autorais e concedem à revista ENSIN@ UFMS - ISSN 2525-7056 o direito de primeira publicação, com o trabalho simultaneamente licenciado sob a Licença Creative Commons Attribution (CC BY-NC-SA 4.0), que permite compartilhar e adaptar o trabalho, para fins não comerciais, reconhecendo a autoria do texto e publicação inicial neste periódico, desde que adotem a mesma licença, compartilhar igual.

\section{EDITORES}

Patricia Helena Mirandola Garcia, Eugenia Brunilda Opazo Uribe, Gerson dos Santos Farias.

\section{HISTÓRICO}

Recebido em: 09/09/2021 - Aprovado em: 28/11/2021 - Publicado em: 15/12/2021.

\section{COMO CITAR}

FALQUI, L. F. A; SOUZA, F. P. Soma 15: O Jogo da Escopa utilizado como Ferramenta para o Ensino da Matemática. Revista ENSIN@ UFMS, Três Lagoas, v. 2, número especial, p. 313-331. 2021. 